\title{
Avaliação da Resistência Interlaminar do Compósito PEl/Fibras de Carbono Soldado pelo Método de Resistência Elétrica
}

\author{
Jonas Frank Reis ${ }^{1}$, Ana Beatriz Moreira Abrahao², Michelle Leali Costa ${ }^{1}$, Edson Cocchieri Botelho ${ }^{1}$ \\ 1 Universidade Estadual Paulista - UNESP, Faculdade de Engenharia, Departamento de Materiais e Tecnologia, Guaratinguetá, \\ SP, Brasil. \\ 2 Faculdade de Tecnologia de Pindamonhangaba - FATEC, Pindamonhangaba, SP, Brasil.
}

Recebido: 25 Abr., 2016

Aceito: 19 Set., 2016

E-mails: jonasfrankreis@gmail.com (JFR), biaengineer@yahoo.com.br (ABMA)
Resumo: O presente trabalho tem como principal objetivo avaliar a efetividade do processo de soldagem por resistência elétrica em compósitos de matriz poli (éterimida) reforçados com fibras contínuas de carbono, a partir do estudo das propriedades térmicas e mecânicas da junta soldada. Para a avaliação das propriedades térmicas, as amostras do material soldado foram submetidas às análises por termogravimetria e por análise termomecânica. Já com o intuito de se estudar a interface resultante da soldagem, estudos foram realizados a partir dos ensaios de cisalhamento ILSS e Iosipescu, assim como por End-Notched Flexure (ENF). Os resultados das análises térmicas em laminados de PEl/fibras de carbono não soldados mostram que o início da degradação para estes compósitos ocorre a $460{ }^{\circ} \mathrm{C}$, e ainda é evidenciado que a temperatura de transição vítrea para amostras soldadas é aproximadamente $15 \%$ superior aos resultados provenientes de amostras não soldadas. Nos ensaios mecânicos mostram que houve um aumento de $32 \%$ e de $20 \%$, respectivamente, nos resultados de cisalhamento interlaminar por ILSS e por losipescu nas amostras soldadas, quando estas são comparadas a amostras não soldadas. Os resultados do ensaio de ENF apresentam valores satisfatórios de tenacidade à fratura interlaminar nos compósitos soldados em relação aos valores encontrados em literatura.

Palavras-chave: Compósitos; Soldagem por resistência elétrica; Ensaios mecânicos; Análises térmicas.

\section{Evaluation of the Interlaminar Resistance of Composite PEI/Carbon Fibers Welded by Electrical Resistance Method}

\begin{abstract}
This study has as main objective to evaluate the effectiveness of the welding process by electrical resistance in composite poly (éterimida) matrix reinforced with continuous fibers of carbon, from the study of the thermal and mechanical properties of the welded joint. To evaluate the thermal properties of the welded material samples were subjected to analysis by thermogravimetry and by thermomechanical analysis. With the intention to study the resulting weld interface, studies were made from the shear tests ILSS and Iosipescu, as well as end-Notched Flexure (ENF). The results of the thermal analysis in laminated PEI / carbon fiber non-welded show that the beginning of degradation for these composites is $460{ }^{\circ} \mathrm{C}$, and it is also evident that the glass transition temperature of welded samples is about $15 \%$ higher than the results from samples not welded. In the mechanical tests show that there was an increase of $32 \%$ and $20 \%$ respectively in interlaminar shear results for the ILSS and losipescu welded samples, when they are compared to samples not welded. The ENF test results show satisfactory values of interlaminar fracture toughness in the composite welded from the values found in literature.
\end{abstract}

Key-words: Composites; Electrical resistance welding; Mechanical test; Thermal analyses.

\section{Introdução}

As matrizes poliméricas atualmente disponíveis para compósitos avançados têm evoluído progressivamente como alternativa para a indústria aeronáutica sendo que, nos últimos anos, diversas matrizes termoplásticas especiais e de alto desempenho vêm sendo estudadas para utilização na fabricação de compósitos estruturais [1].

Nos últimos anos, o número de peças e estruturas metálicas substituídas por compósitos poliméricos, não somente na aviação militar, mas também em projetos de aeronaves civis vem crescendo substancialmente. Um exemplo deste fato por ser visto
Este é um artigo publicado em acesso aberto (Open Access)
sob a licença Creative Commons Attribution Non-Commercia que permite uso, distribuição e reprodução em qualquer meio, sem restrições desde que sem fins comerciais e que 0 trabalho original seja corretamente citado. 
na aeronave $\mathrm{A} 380$ da Airbus, onde $22 \%$ de sua massa total é constituída de materiais compósitos. Portanto, a aplicação de materiais compósitos já é uma realidade principalmente na indústria aeroespacial.

Por outro lado, um dos principais problemas da utilização de compósitos termoplásticos em aplicações estruturais consiste em sua união efetiva para a integração de diferentes componentes, devido a ocorrência de defeitos, consequentes a essa união, tais como: concentrações de tensões provocadas por orifícios na estrutura quando rebitadas, a demora do processo de cura de sistemas adesivos constituídos de resinas termorrígidas, a desconsolidação para os processos de união por co-consolidação [1,2].

A avaliação da viabilidade para a utilização do processo de soldagem por resistência elétrica visando à integração de laminados termoplásticos para aplicações aeronáuticas é uma questão nova, principalmente no Brasil. Dentre as diversas técnicas de soldagem atualmente utilizadas para compósitos, a técnica de soldagem por resistência elétrica vem se destacando, principalmente por proporcionar economia de material, pois não necessita de consumíveis de soldagem ou meios auxiliares para a união, descarta o uso de rebites, parafusos, porcas, e também não necessita de serviços de usinagem, além de poder ser utilizada na união de peças com arquitetura complexa [2,3].

A Figura 1 apresenta uma ilustração de um sistema padrão para a realização da soldagem por resistência de compósitos poliméricos. A partir deste modelo, pode ser evidenciada a necessidade da utilização de um elemento resistivo, grampos conectores para a passagem de corrente elétrica, fornecimento de energia elétrica, dispositivos de fixação, fios, voltímetro e amperímetro. As medições de temperatura evolvidas neste processo são realizadas a partir da utilização de termopares [4].

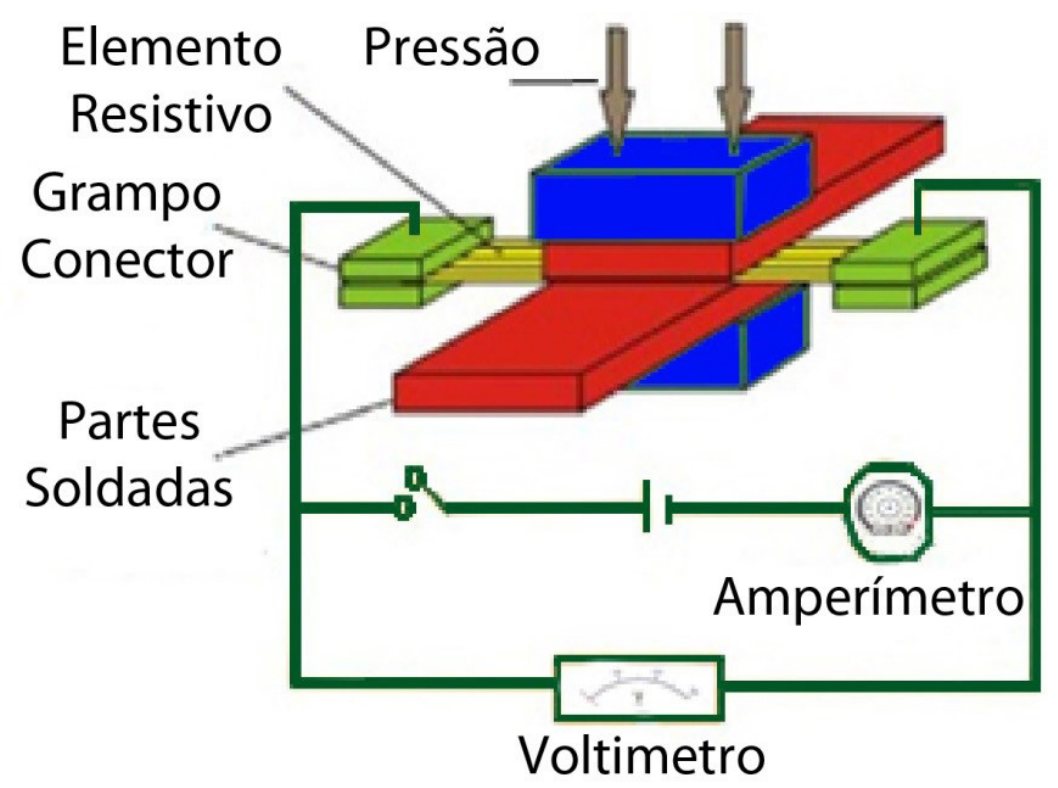

Figura 1. Ilustração de um sistema de soldagem por resistência elétrica para compósitos poliméricos [2].

Basicamente, este processo consiste na utilização de elementos resistivos unidos entre as superfícies de ligação dos laminados para proporcionar o calor necessário para a junção a partir do efeito Joule. Uma corrente elétrica é aplicada ao elemento resistivo ocasionando o aumento de sua temperatura. A temperatura do elemento resistivo aumenta consideravelmente na interface, fundindo o compósito e, consequentemente, promovendo a soldagem do laminado sob aplicação de pressão [1,3].

As juntas soldadas são particularmente interessantes para unir materiais avançados de elevada resistência mecânica, como é o caso dos compósitos de matriz polimérica PEI (poli (éter-imida)) utilizados neste estudo [5]. O PEI é considerado como um excelente candidato para ser utilizado como matriz em compósitos avançados, 
Avaliação da Resistência Interlaminar do Compósito PEl/Fibras de Carbono Soldado pelo Método de Resistência Elétrica

apresentando como principais vantagens: boa resistência mecânica e rigidez a temperaturas elevadas; elevada resistência térmica; boas propriedades eléctricas e apropriada resistência química [6,7].

Entretanto, os métodos de inspeção da soldagem para compósitos de uso estrutural, não acompanharam o ritmo de desenvolvimento da técnica em si. Atualmente, os mesmos métodos que vêm sendo utilizados para testar processos convencionais de união, tais como o uso de rebites, parafusos e porcas, são utilizados para avaliar a resistência e a qualidade das juntas [8,9].

Existem alguns processos de união que estão disponíveis para unir estruturas de compósitos termoplásticos que requerem grandes quantidades de aquecimento da peça. Dentre destas técnicas, o processo de co-consolidação deve ser comentado. Este método de união é ideal para a união de laminados, em que nenhum peso é adicionado à estrutura final do laminado, nenhum material é introduzido na linha de adesão fibra/matriz, não é necessária qualquer preparação da superfície e a força de ligação é potencialmente igual ao do laminado original. Entretanto, todo o processo de união por este método é trazido para a temperatura de fusão do laminado, e isso implica geralmente a necessidade de ferramentas complexas e muito caras (diferentemente se comparado aos processos de soldagem) para manter a pressão em toda a parte do material para evitar a desconsolidação [10].

Devido às características anisotrópicas dos compósitos poliméricos avançados, tornou-se evidente ao longo dos anos que a fratura interlaminar é potencialmente um dos principais processos de falha que limita a vida de um determinado componente, principalmente devido à ausência de reforço ortogonal ao plano das fibras. Este fato torna-se ainda mais crítico em compósitos soldados [11,12].

A fratura interlaminar é designada habitualmente por delaminação, uma falha associada à interface entre as camadas de um compósito polimérico. Desta forma, fraturas interlaminares descrevem falhas orientadas entre as camadas, ocorrendo no plano do laminado, fraturando principalmente a matriz, com poucas ou nenhuma fratura de fibra $[13,14]$.

A ação conjunta de todos estes fatores no comportamento e durabilidade dos compósitos é um fenômeno bastante complexo que ocorre a nível molecular. $O$ estudo deste fenômeno e a interpretação do comportamento resultante são tarefas cruciais para a determinação da vida útil e segurança das estruturas produzidas em material compósito [15].

O objetivo deste trabalho é de se avaliar a eficiência do processo de soldagem por resistência elétrica, através da avaliação da resistência interlaminar nos compósitos soldados, constituído de matriz PEI reforçada com fibra de carbono. Para isso, ensaios mecânicos envolvendo cisalhamento interlaminar por ILSS e losipescu, assim ensaios de ENF (End Notched Test) para a obtenção do modo de falha $G_{\| l}$ foram realizados.

\section{Materiais e Métodos}

\subsection{Laminados}

Os laminados que foram submetidos à soldagem por resistência elétrica foram fornecidos pela empresa holandesa TenCate Advanced Composites. Estes laminados foram confeccionados com tecidos na configuração 8 HS e espessura nominal de $2,0 \mathrm{~mm}$. O laminado de PEl/fibra de carbono foi confeccionado com tecidos na configuração $8 \mathrm{HS}$ com espessuras nominais entre 2 a 3,5mm, e com configuração $(0 / 90)_{55^{\prime}}$ contendo aproximadamente $50 \%$ em volume de matriz.

\subsection{Propriedades térmicas}

Visando a obtenção das características térmicas dos laminados soldados, foram realizadas as análises de termogravimetria (TGA) e de análise termomecânica (TMA).

\subsubsection{Análise termogravimétrica (TGA)}

Antes da realização da soldagem, foi necessária a avaliação da temperatura de segurança, ou seja, da temperatura de degradação da matriz polimérica (PEI). Com esta finalidade, foi realizada a análise termogravimétrica (TGA) em um analisador modelo TG-DTA 6200 da marca SII-Nanotechnology, utilizando método dinâmico com aquecimento de $35^{\circ} \mathrm{C}$ até $1000^{\circ} \mathrm{C}$, taxa de aquecimento de $10^{\circ} \mathrm{C} / \mathrm{min}$ e uma atmosfera de ar sintético (fluxo de $100 \mathrm{~mL} / \mathrm{min}$ ). 


\subsubsection{Análise termomecânica (TMA)}

A análise termomecânica (TMA) é uma técnica que permite estudar as propriedades dos materiais em função da variação da temperatura. Este processo consiste em medir as variações dimensionais da amostra em função da temperatura, ao mesmo tempo em que a amostra é solicitada mecanicamente. Esta técnica, na área dos polímeros, é essencialmente utilizada para determinar o coeficiente de expansão térmica e medir a temperatura de transição vítrea [16].

Dessa forma, foi realizada a análise envolvendo TMA, visando avaliar a temperatura de transição vítrea da matriz polimérica e analisar a influência do comportamento do coeficiente de expansão térmica linear do compósito PEl/fibra de carbono frente ao processo de soldagem. Com esta finalidade, foram realizadas análises em um equipamento TMA/SS 6100 (Thermo Mechanical Analysis), da marca SII Nanotechnology Inc da Seiko. As condições utilizadas de análise foram: faixa de temperatura entre $30^{\circ} \mathrm{C}$ a $230^{\circ} \mathrm{C}$, sendo a taxa de aquecimento de $3{ }^{\circ} \mathrm{C} / \mathrm{min}$ e uma atmosfera de nitrogênio (fluxo de $100 \mathrm{~mL} / \mathrm{min}$ ), segundo a norma ASTM E831. As amostras foram cortadas em fresas e lixadas para a obtenção de dimensões repetitivas de $8,0 \mathrm{~mm} \times 8,0 \mathrm{~mm}$ e $2 \mathrm{~mm}$ (4 mm para as amostras soldadas) (comprimento $\times$ largura $\times$ espessura).

\subsection{Soldagem}

Como o objetivo do trabalho é realizar um método de soldagem para os laminados que são disponíveis dentro do mercado, não foi necessária a inserção de filmes de PEI na junta montada. Para a realização da soldagem, foi utilizada uma máquina de soldagem por resistência elétrica para compósitos, confeccionada pela empresa AUMEK em parceria com a Faculdade de Engenharia de Guaratinguetá (UNESP). Na soldagem, foram utilizadas malhas metálicas de aço inoxidável AISI 304 de 300 fios por polegadas, como elementos resistivos para o processo. A Figura 2 apresenta, de forma representativa, a configuração das malhas metálicas, com o posicionamento da urdume e a trama deste material, que são indicadas pelas setas (1) e (2), respectivamente. As amostras foram

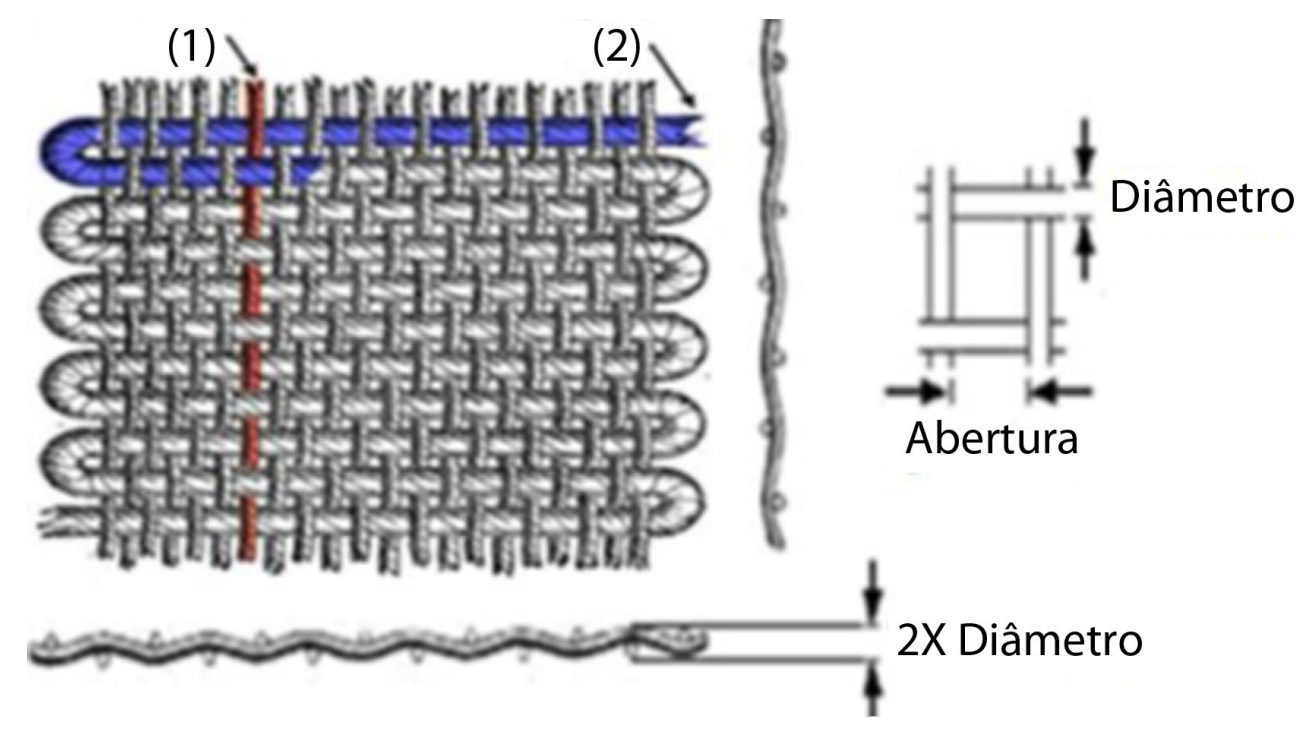

Figura 2. Representação esquemática da malha Al 304 de 300 fios por polegadas utilizada no estudo [17].

soldadas utilizando os seguintes parâmetros: Corrente: 50 A, Tempo: 80 s e Pressão: 0,7 MPa. Esses parâmetros de soldagem estabelecidos no estudo foram baseados na literatura [18,19], através do modelo estatístico de planejamento experimental fatorial.

\subsection{Propriedades mecânicas}

Ensaios mecânicos de ILSS (Interlaminar Short Beam), losipescu e ENF (End Notched Flexure) foram realizados visando à obtenção da resistência interlaminar nos compósitos soldados, frente a esforços de cisalhamento. A Tabela 1 resume os ensaios mecânicos com as dimensões dos corpos de provas de $\mathrm{PEI} /$ carbono não soldados e soldados. 
Avaliação da Resistência Interlaminar do Compósito PEl/Fibras de Carbono Soldado pelo Método de Resistência Elétrica

Tabela 1. Resumo dos ensaios mecânicos realizados no estudo com suas respectivas dimensões.

\begin{tabular}{ccc}
\hline Ensaios & \multicolumn{2}{c}{ Dimensões (Comprimento x largura x espessura) } \\
Materiais & PEl/carbono não soldado & PEl/carbono soldado \\
ILSS & $24 \times 6,35 \times 2 \mathrm{~mm}$ & $24 \times 6,35 \times 4 \mathrm{~mm}$ \\
losipescu & $76 \times 20 \times 2 \mathrm{~mm}$ & $76 \times 20 \times 4 \mathrm{~mm}$ \\
ENF & Não Realizado & $125 \times 25 \times 4 \mathrm{~mm}$ \\
\hline
\end{tabular}

\subsubsection{Ensaio ILSS (Interlaminar Short Beam)}

O ensaio de ILSS (Interlaminar short beam) foi realizado neste trabalho com o intuito de avaliar a resistência ao cisalhamento interlaminar e comparar esta propriedade com o cisalhamento na região soldada. Os ensaios foram realizados com uma célula de carga de 10 kN em uma máquina universal de ensaios mecânicos da Shimadzu, modelo AG-X, de acordo com a norma ASTM D2344. Com este propósito, 10 (dez) corpos de provas foram ensaiados para cada caso estudado.

\subsection{2. losipescu}

O método de cisalhamento por losipescu foi realizado em um corpo de prova retangular com entalhes em V. As dimensões dos corpos de prova e as condições de ensaio foram baseadas na norma ASTM D5379. Para este ensaio, o entalhe possui um raio padronizado de 1,3mm, com o propósito de evitar interferências nos resultados devido à presença de cantos vivos.

\subsubsection{ENF (End Notched Flexure)}

O ensaio ENF (End-Notched Flexure) é realizado com o propósito da obtenção do modo de falha II de fratura interlaminar. O modo II corresponde a um carregamento cisalhante no plano e causa um "escorregamento" entre as superfícies da falha em direções opostas. Quando estruturas fabricadas de materiais compósitos estão sujeitas a um carregamento do modo II, a camada interlaminar é a primeira a falhar. As falhas interlaminares ocorrem em planos paralelos aos das camadas e seus mecanismos de falha e aparência tendem a ser dominados por fratura da matriz e separação da fibra da matriz, causando uma das falhas mais presentes nos compósitos, a delaminação.

Esta falha pode ocorrer devido às tensões de cisalhamento como também por tensões transversais que surgem na região interlaminar, quando o material está sob flexão. A delaminação muitas vezes resulta na perda de rigidez e resistência, o que pode levar a problemas de segurança e confiabilidade de uma determinada estrutura.

O ensaio ENF foi realizado com base na norma ASTM D7905, com as seguintes medidas dos corpos de prova: $\mathrm{a}=45 \mathrm{~mm}, \mathrm{~L}=120 \mathrm{~mm}, 2 \mathrm{~h}=4 \mathrm{~mm}$ e largura $=25 \mathrm{~mm}$. A Figura 3 ilustra a geometria do corpo de prova para o ensaio ENF. O monitoramento foi realizado visualmente, com as marcações realizadas em todos os corpos

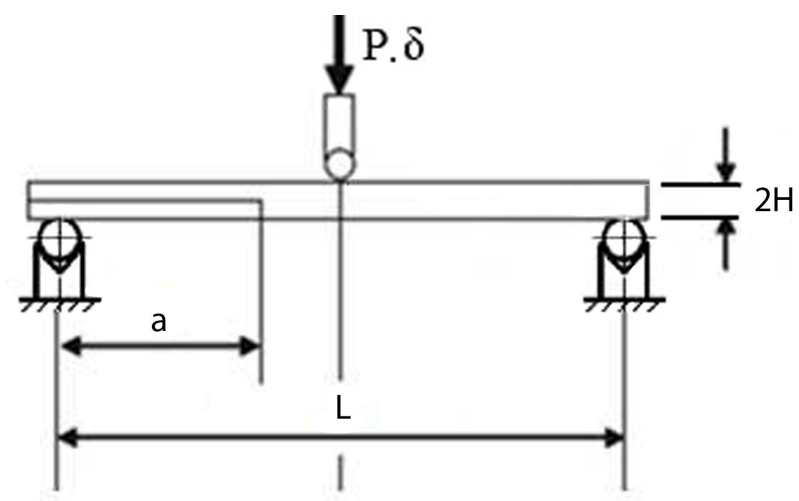

Figura 3. Método de ensaio ENF para a medição da tenacidade à fratura interlaminar de compósitos, onde: $a=$ comprimento da trinca $(m), P=$ força $(N), \ddot{a}=$ deslocamento $(m), h=$ espessura do corpo de prova, $L=$ distância entre os apoios (m) [14]. 
de prova e a partir da obtenção do gráfico Carga X Deslocamento foi realizado o cálculo da tenacidade a fratura interlaminar no modo II.

O ensaio de ENF foi realizado em uma máquina universal de ensaios Shimadzu, modelo AG-X, a uma velocidade de $1 \mathrm{~mm} / \mathrm{min}$, utilizando uma célula de carga de $5 \mathrm{kN}$. A taxa de liberação de energia na fratura em modo II ( $\left.G_{\| c}\right)$ foi calculada segundo a Equação 1:

$$
G_{I I c}=\frac{9 \cdot a^{2} \cdot P \cdot \delta}{2 B \cdot\left(2 L^{3}+3 a^{3}\right)}
$$

O ensaio ENF foi realizado em cinco amostras de PEI/fibras de carbono soldadas, visando à obtenção da tenacidade à fratura interlaminar no modo de falha II, $G_{\| c^{*}}$ O ensaio de ENF realizado no estudo é ilustrado pela Figura 4, onde foi fotografado em detalhes o processo de crescimento da trinca durante o ensaio até a ruptura do material soldado.

A Figura 4a foi tirada a foto no inicio do crescimento da trinca, onde a trinca havia percorrido $15 \mathrm{~mm}$. A Figura $4 \mathrm{~b}$ ilustra o crescimento continuo da trinca, crescimento esse que se manteve no centro da amostra soldada (na região de união dos laminados), com a trinca percorrendo $6 \mathrm{~mm}$. A Figura $4 \mathrm{c}$ apresenta a trinca antes da ruptura do material, podendo-se observar a trinca percorrendo em torno de $25 \mathrm{~mm}$. Finalmente, a Figura $4 \mathrm{~d}$ mostra o momento que o material sofre a carga total e, consequentemente, a sua ruptura, sendo que o comprimento final da trinca observada no momento da falha chegou a $35 \mathrm{~mm}$. Este ensaio é, essencialmente, um teste de flexão em três pontos, onde uma amostra é posicionada sobre dois apoios e uma força é aplicada no centro da peça [14].

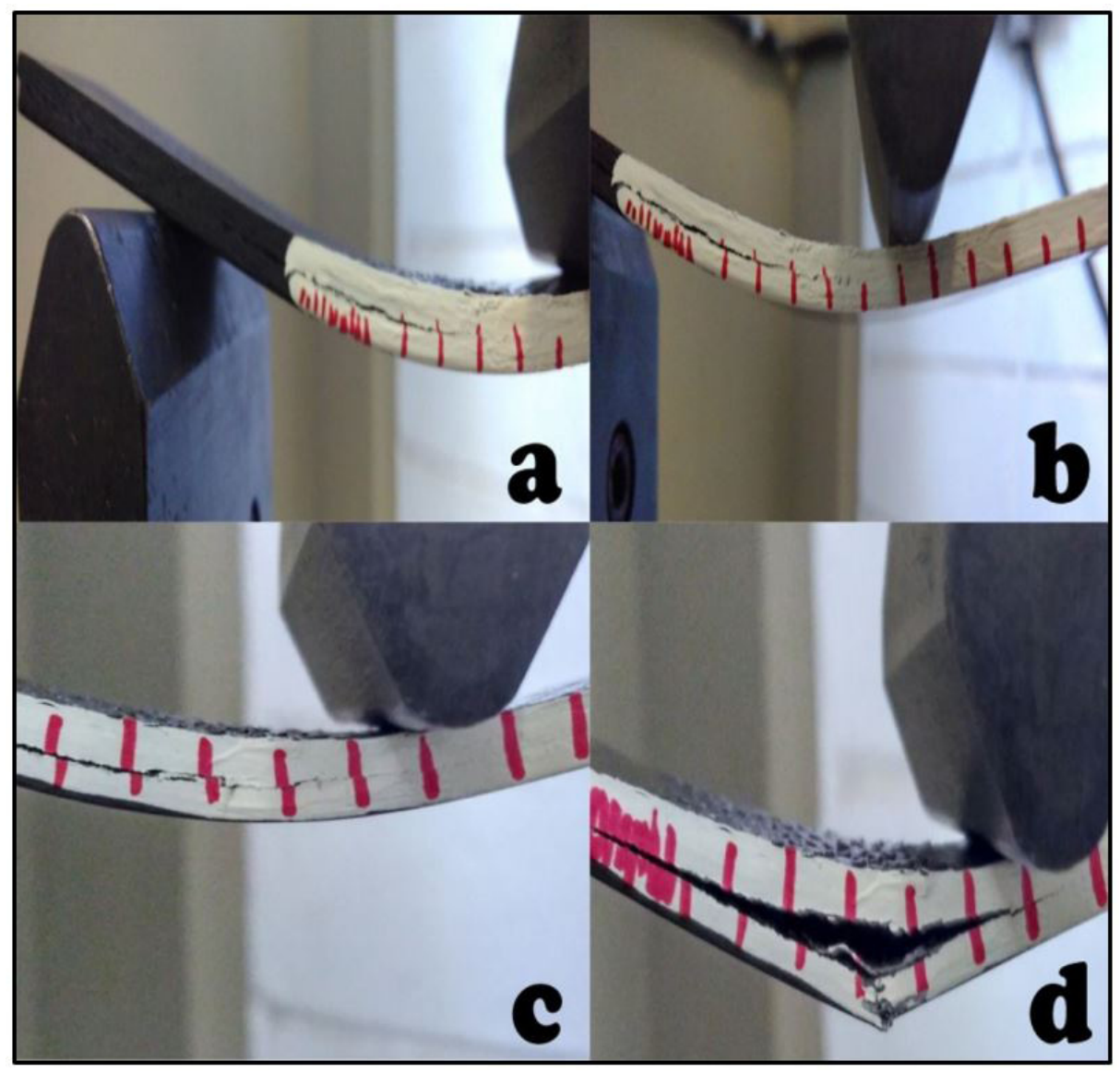

Figura 4. Ensaio ENF realizado no compósito PEI/carbono: (a) Crescimento inicial da trinca; (b) Crescimento continuo da trinca da ruptura; (c) Detalhe aproximado da trinca antes da ruptura; (d) Ruptura do material. 
Avaliação da Resistência Interlaminar do Compósito PEl/Fibras de Carbono Soldado pelo Método de Resistência Elétrica

\subsection{Microscopia óptica}

Para a caracterização dos laminados, análises foram realizadas por microscopia óptica utilizando um estereomicroscópio da marca Zeiss AXIO Imager Z2m, realizando a técnica de reconstrução por extensão de foco, em campo claro, utilizando uma objetiva LD EC Epiplan-Neofluar 50x/0.55HD DIC M27, disponível no Laboratório de Imagens da FEG/UNESP.

\section{Resultados e Discussão}

\subsection{Avaliação do processo de soldagem}

A determinação da janela do processo de soldagem, ou seja, das temperaturas mínima e máxima a que a matriz polimérica deve suportar, consiste em uma condição essencial para que as peças formem juntas eficientes e com valor máximo de resistência de união. Esta temperatura deve ser acima daquela necessária para que a matriz "amoleça" (temperatura de transição vítrea), porém, não deve exceder valores muito acima destes visando evitar a ocorrência da degradação do material. De acordo com a literatura, para a soldagem de polímeros termoplásticos, especificamente aqueles que são amorfos como é o caso do PEI, a temperatura que se deve ter como referência para o processo de soldagem é a de transição vítrea ( $\mathrm{Tg}$ ) (ou seja, a soldagem deve ocorrer em temperatura superior da Tg do material estudado), tendo o cuidado de não ultrapassar a temperatura de degradação do polímero em questão [20].

Com o objetivo de se conhecer a temperatura máxima que pode ser atingida durante o processo de soldagem, assim como se conhecer o comportamento termo-degradativo da matriz PEI, foram realizadas análises de TGA na amostra estudada. A partir da Figura 5, referente ao laminado PEl/fibra de carbono, foi possível observar que o início da decomposição térmica do material ocorre na temperatura de $430^{\circ} \mathrm{C}$. Como a análise foi realizada em ar sintético, a fibra de carbono foi termo oxidada não restando resíduo final na análise.

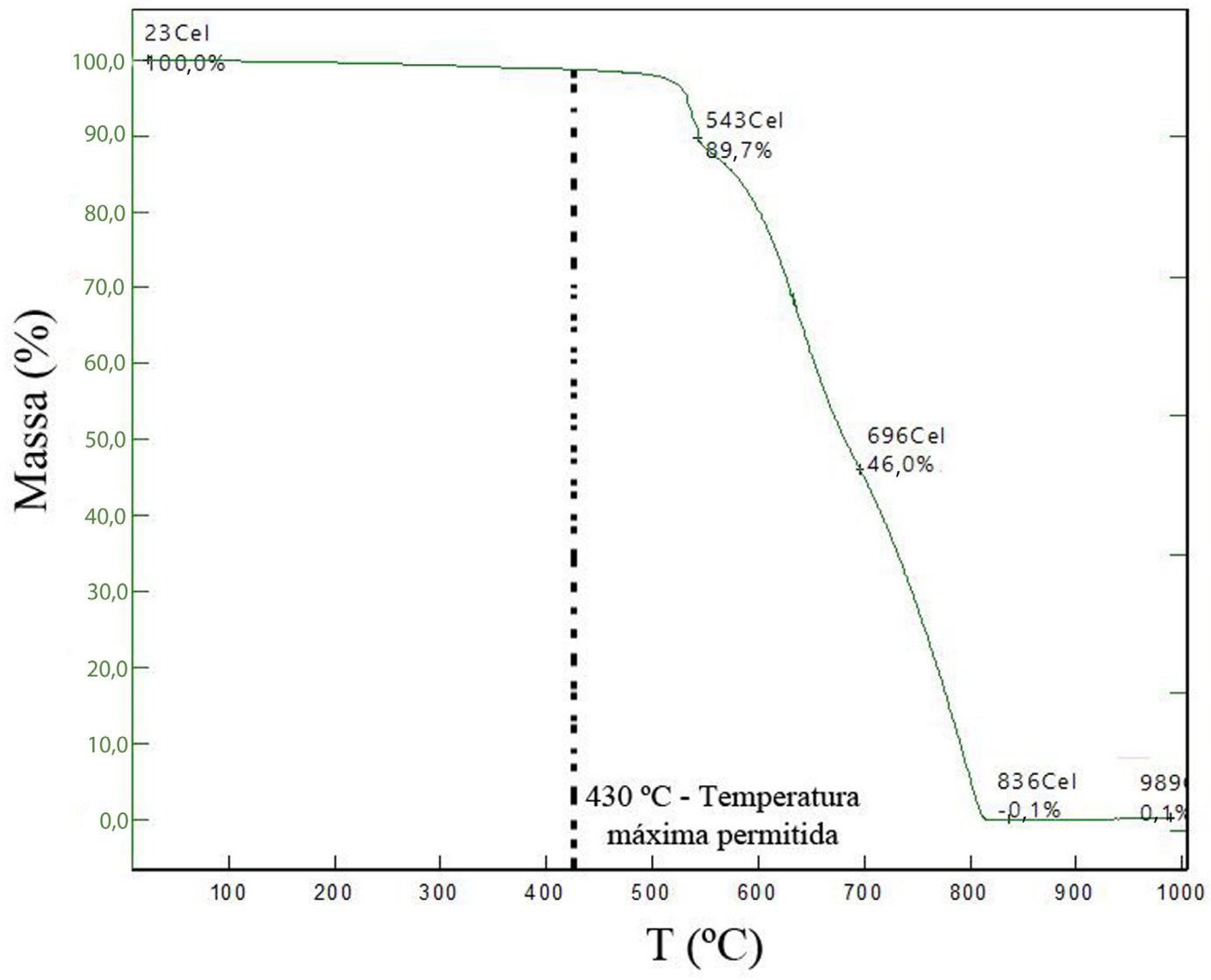

Figura 5. Gráfico de TGA obtido para o compósito PEl/fibra de carbono. 
A Figura 6 apresenta os resultados de TMA provenientes de amostras do laminado de PEI/fibra de carbono com o propósito de avaliar a temperatura de transição vítrea (Tg) e coeficiente de expansão térmica linear do laminado soldado e não soldado. A Tg foi determinada pelo ponto de intersecção entre as curvas referentes à zona vítrea e à zona onde existe um comportamento que se assemelha a borracha. A partir dos resultados encontrados, pode ser observado que a matriz PEl apresenta uma $\mathrm{Tg}$ em $163^{\circ} \mathrm{C}$.

$\mathrm{Na}$ Figura 6 pode-se observar que o valor de $\alpha$ (coeficiente de dilatação linear) encontrado para o compósito soldado foi de $69.10^{-6} /{ }^{\circ} \mathrm{C}$, ou seja, maior do que ao compósito de PEI/fibra de carbono não soldado (cerca de $23 \%$ ), porém encontram-se dentro da mesma ordem de grandeza. Este fato indica que a malha metálica não reduz $o$ coeficiente de expansão térmica linear do compósito polimérico como era esperado, devido à presença de um elemento metálico (que possui menor valor do coeficiente de expansão térmico linear) que, por sua vez, possui um valor de $\alpha$ menor (aço inoxidável $11,7.10^{-6} /{ }^{\circ} \mathrm{C}$ ) [21,22].

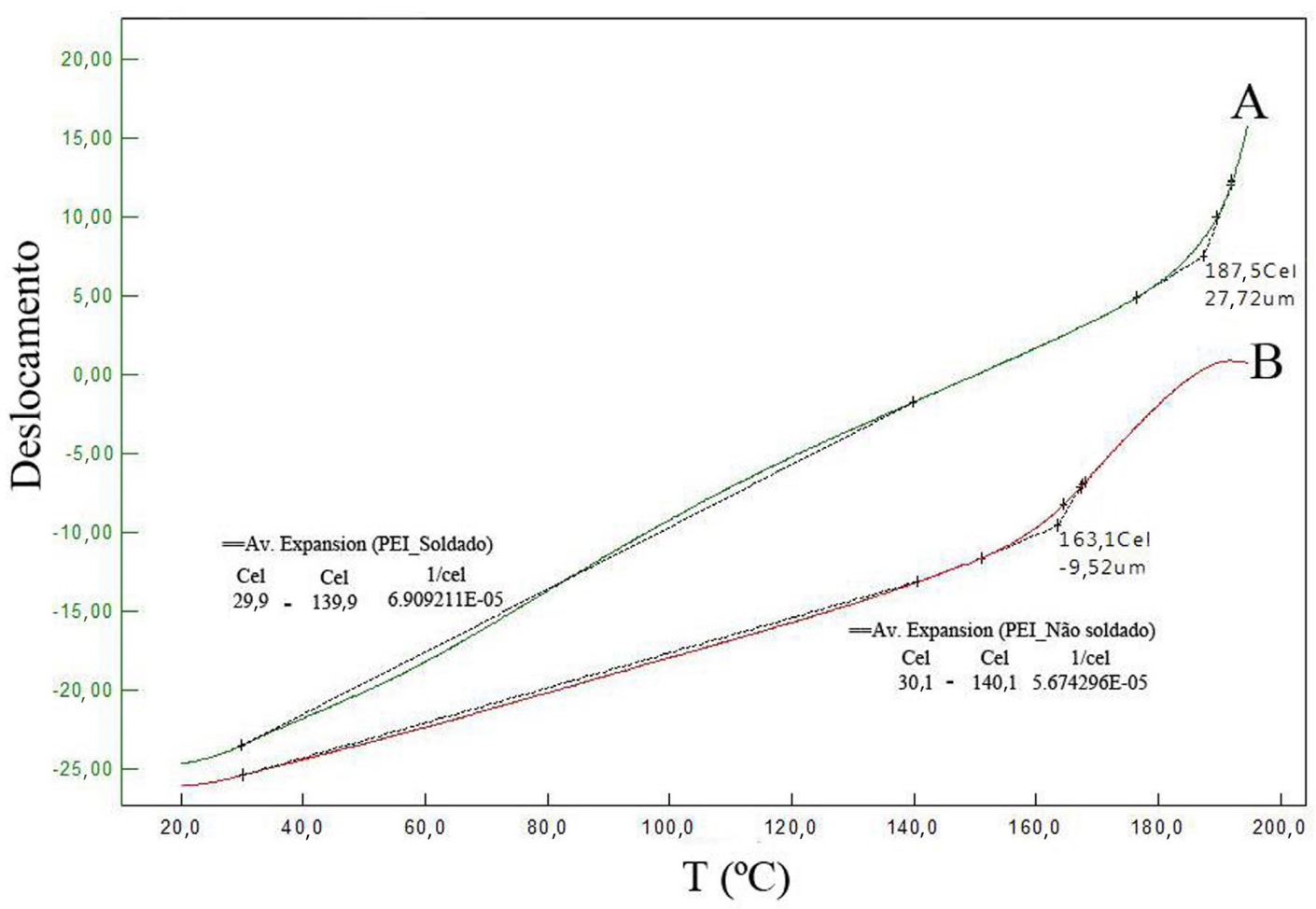

Figura 6. Gráfico de TMA obtido para o compósito PEl/fibra de carbono soldado (A) e não soldado (B).

Desta forma, a partir dos resultados encontrados, pode-se concluir que a janela para a soldagem deste laminado encontra-se entre $180^{\circ} \mathrm{C}$ até $400{ }^{\circ} \mathrm{C}$, considerando um fator de segurança tanto com relação a temperatura de transição vítrea quanto de degradação deste material. Assim, para a determinação da janela de processamento dos materiais estudados no presente trabalho, foram consideradas as análises térmicas realizadas por TMA e TGA, e adicionalmente um estudo na máquina de soldagem considerando a observação em relação á degradação do material.

A temperatura de transição vítrea obtida por TMA nos laminados de matriz polimérica PEI não soldados $\left(163^{\circ} \mathrm{C}\right)$, é inferior aos valores de transição vítrea aos encontrados na literatura para o polímero PEI (entre $180-217^{\circ} \mathrm{C}$ ) [23]. De acordo com a literatura [20], para a soldagem de polímeros termoplásticos, especificamente aqueles que são amorfos, como é o caso do PEI, a temperatura que se deve ter como referência para o processo de soldagem é a de transição vítrea ( $\mathrm{Tg}$ ) (ou seja, a soldagem deve ocorrer em temperatura superior da Tg do material estudado), tendo o cuidado de não ultrapassar a temperatura de degradação do polímero em questão. A partir da Tg as cadeias atingem maior mobilidade, permitindo transferência de massa por difusão através da interface. 
Avaliação da Resistência Interlaminar do Compósito PEl/Fibras de Carbono Soldado pelo Método de Resistência Elétrica

No processo de soldagem por resistência elétrica a temperatura é um fator importante, pois tem que atingir um valor suficiente para o aquecimento das peças. Entretanto, o valor de temperatura não deve exceder muito a temperatura de transição vítrea do polímero formem juntas sem degradação do material e com valor máximo de resistência de união [24].

A Figura 7 apresenta os resultados provenientes dos ensaios preliminares indicando a temperatura máxima atingida durante o processo de soldagem por resistência elétrica.

Como pode ser observada na Figura 7, a temperatura máxima atingida neste caso foi de $378{ }^{\circ} \mathrm{C}$, sendo que a temperatura de degradação inicial observada para este laminado pela técnica de TGA foi de $430{ }^{\circ} \mathrm{C}$. Com isso, a partir do resultado do gráfico da medida de temperatura da soldagem preliminar, o laminado foi soldado sem degradação, com a temperatura máxima obtida pelo processo de soldagem mantendo-se na janela de temperaturas de soldagem $\left(163-430^{\circ} \mathrm{C}\right)$ obtida pelas análises térmicas realizadas.

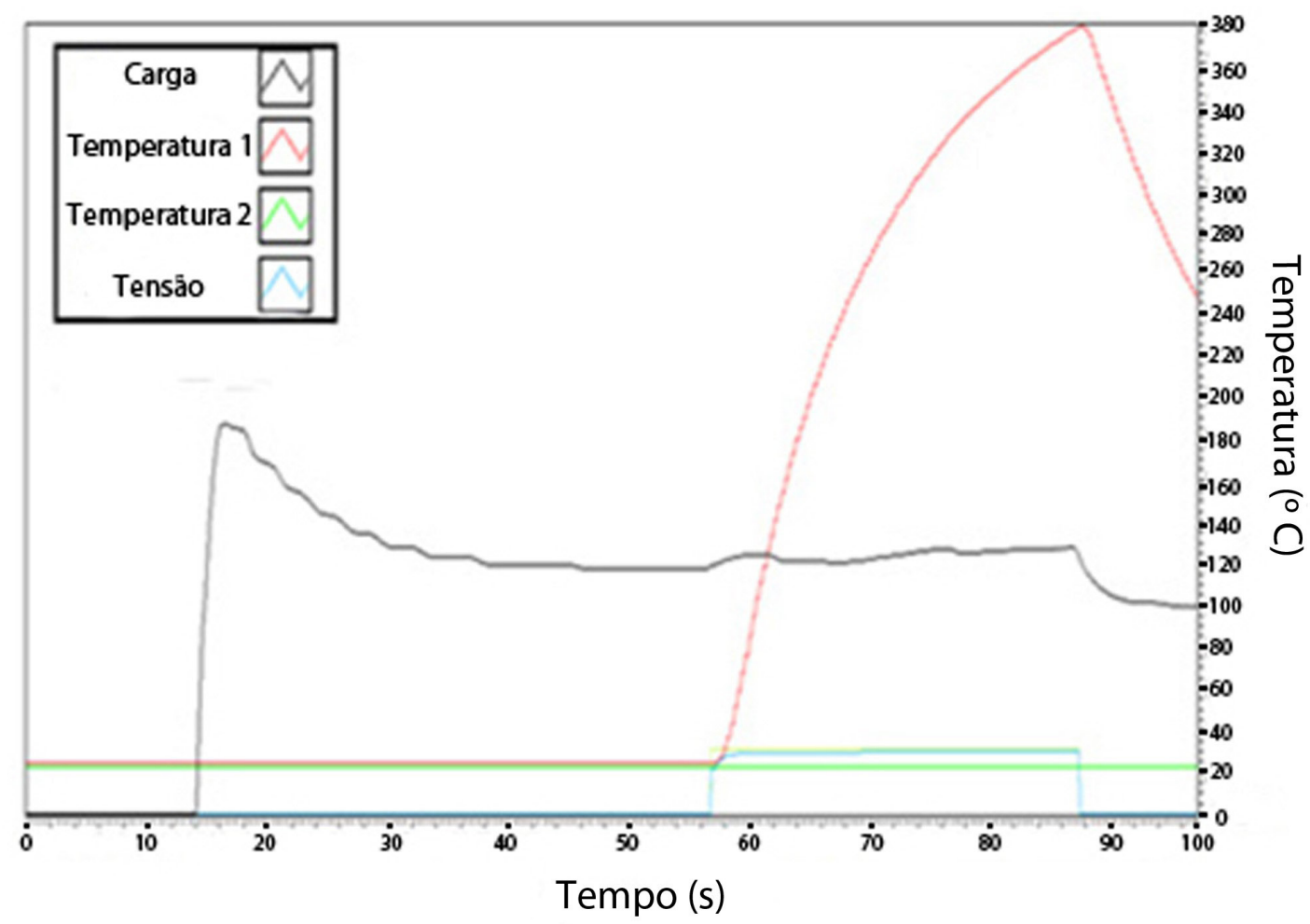

Figura 7. Resultados da temperatura atingida durante o processo de soldagem por resistência elétrica para o compósito $\mathrm{PEl} /$ fibra de carbono, onde que a temperatura 1 é a temperatura em que se obtém no processo e a temperatura 2 é a temperatura ambiente.

Após o processo de soldagem, a junta obtida foi avaliada por microscopia óptica (MO). As Figuras 8a-d apresentam imagens da região transversal de um corpo de prova soldado de PEl/fibras de carbono obtidas por microscopia óptica.

As setas vermelhas indicam a interface soldada para o $\mathrm{PEl} /$ fibras de carbono, sendo que os pontos brilhantes nas figuras representam regiões da malha metálica utilizada como elemento resistivo. A partir destes resultados pode ser observado que o processo de soldagem apresentou uma interface homogênea entre as lâminas soldadas em relação à região em que não houve interferência do aquecimento local durante o processo de soldagem. Adicionalmente, nas micrografias, foi possível identificar evidências da boa interação entre a malha metálica com a matriz polimérica PEI. Foi possível, ainda, observar a aparição de poros no material, indicadas pelas setas azuis na Figura 8, podendo ser supostamente originados de um resultado da degradação térmica (evolução de gases) do 


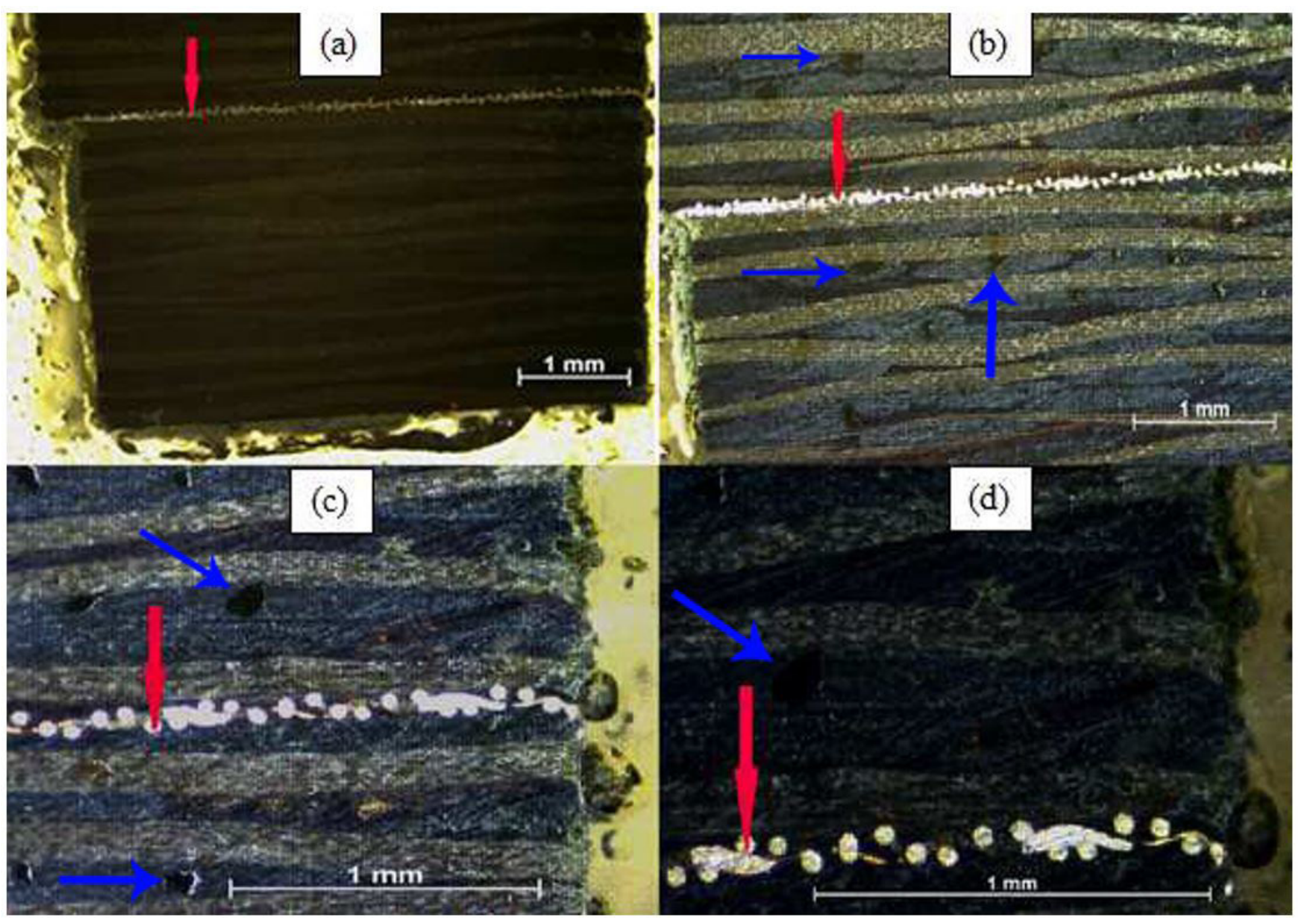

Figura 8. Microscopia da região transversal da amostra soldada de PEl/fibras de carbono soldado: (a) Ampliação de 6,5X; (b) Ampliação de 10x; (c) - Ampliação de 20x; (d) - Ampliação de 40x.

laminado ou também pela presença de umidade no ar no qual, durante a solidificação do laminado, a evaporação da umidade dissolvida na resina do PEI, que pode ter causado o aparecimento da porosidade [25].

\subsection{Avaliação do cisalhamento interlaminar por ILSS e losipescu}

Os resultados obtidos a partir da análise mecânica da junta soldada por ILSS e losipescu em comparação com os valores do material sem solda deste estudo (laminado de PEI/fibras de carbono) são apresentados na Tabela 2.

Tabela 2. Valores de resistência ao cisalhamento ILSS e losipescu do laminado PEI/fibra de carbono.

\begin{tabular}{cccccc}
\hline \multirow{2}{*}{ Compósitos } & \multicolumn{2}{c}{ ILSS } & & \multicolumn{2}{c}{ losipescu } \\
\cline { 2 - 3 } \cline { 5 - 6 } & $\begin{array}{c}\text { Resistência ao } \\
\text { Cisalhamento (MPa) }\end{array}$ & Desvio Padrão & & $\begin{array}{c}\text { Resistência ao } \\
\text { Cisalhamento (MPa) }\end{array}$ & Desvio Padrão \\
Soldado & 63,7 & 4,03 & & 119,2 & 1,99 \\
Não Soldado & 48,1 & 2,03 & & 100,4 & 0,4 \\
\hline
\end{tabular}

Os resultados obtidos a partir dos ensaios de ILSS mostram que houve um aumento significativo da resistência ao cisalhamento interlaminar nas amostras soldadas, tendo sido este de até 32\%. Este comportamento ocorreu, provavelmente, devido à presença do elemento de aquecimento (aço inoxidável), contribuindo, desta forma, para a melhoria desta propriedade mecânica do laminado. Entretanto, o ensaio de ILSS não proporciona um estado totalmente puro de cisalhamento, mas sim, um estado de tensões combinadas.

Para comprovar a influência do elemento de aquecimento na resistência ao cisalhamento interlaminar, foi realizada uma análise por microscopia óptica com o intuito de avaliar o modo de falha proveniente dos ensaios de 
ILSS para os materiais analisados. As Figuras 9 e 10 apresentam a fratura dos compósitos soldados e não soldados após o ensaio mecânico, sendo indicadas às regiões que foram analisadas por microscopia. A partir dos resultados encontrados nas Figuras 9 e 10, pode ser observado que o laminado de PEl/fibra de carbono apresenta fratura translaminar quando solicitado por cisalhamento interlaminar. Já quando da presença da malha metálica esta fratura ocorre de forma interlaminar, modificando o aspecto de falha deste laminado. Desta forma, a presença da malha metálica auxilia na formação de trincas na interface soldada, que se propagam em toda a extensão do corpo de prova. Portanto, na amostra com solda a trinca se propaga até uma região anterior da solda, não afetando onde é localizado o elemento resistivo (região da solda) e, consequentemente, não se propaga para a parte superior da amostra, como evidenciado pelo circulo na Figura 10b. Adicionalmente, a região do laminado, a região da propagação da trinca e a região da solda, são indicadas pelas setas na Figura 10b.

Fraturas interlaminares têm a tendência de serem influenciadas pela fratura da matriz e pelo descolamento fibra/matriz. Em geral, as condições mais comuns, em que ocorre o descolamento fibra/matriz, são na interface

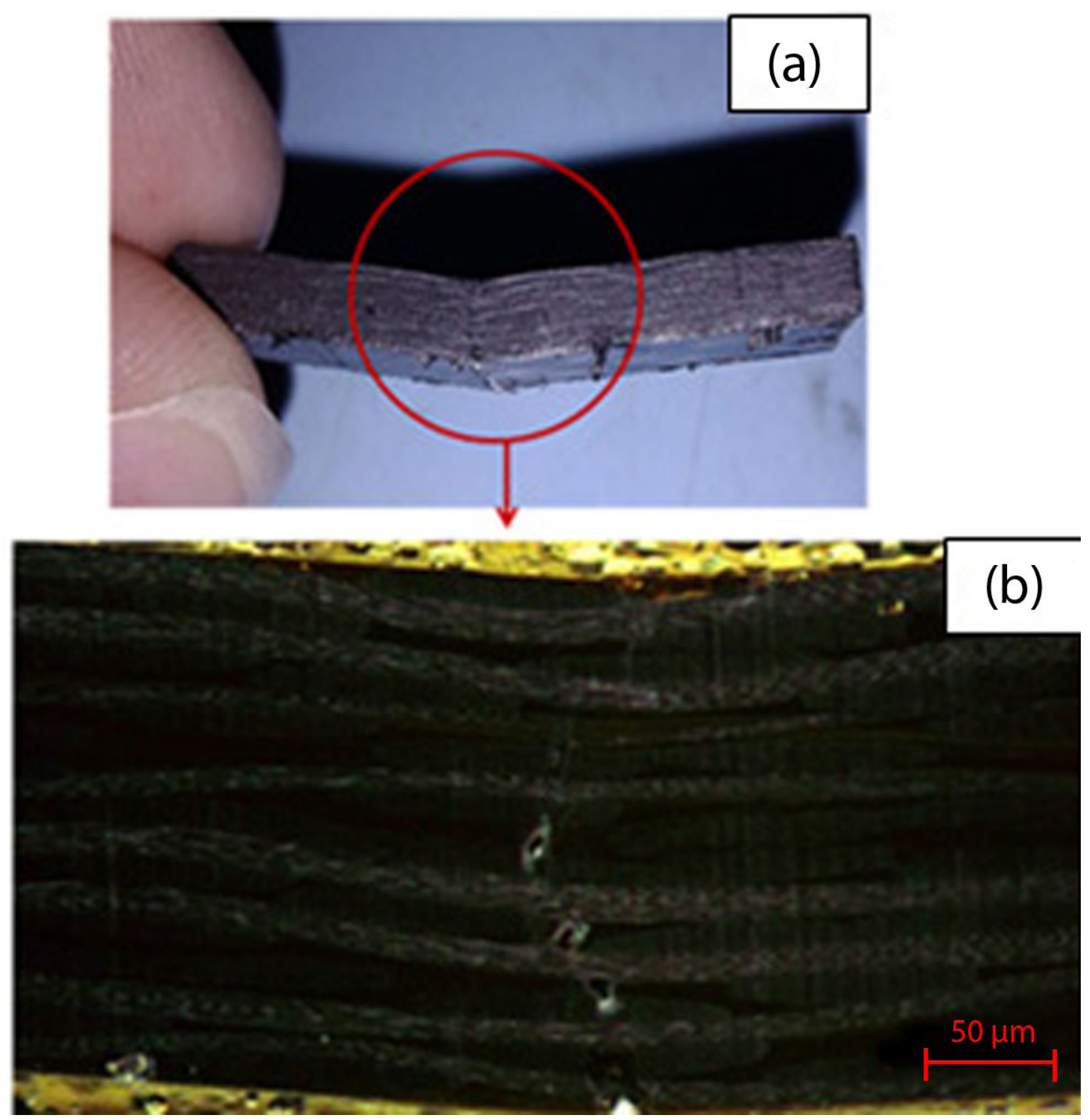

Figura 9. (a) Compósito PEI/fibra de carbono sem solda após o ensaio de ILSS; (b) Micrografia apresentando o início da fratura na região fraturada pelo ensaio de ILSS do laminado PEI/fibra de carbono sem solda. 


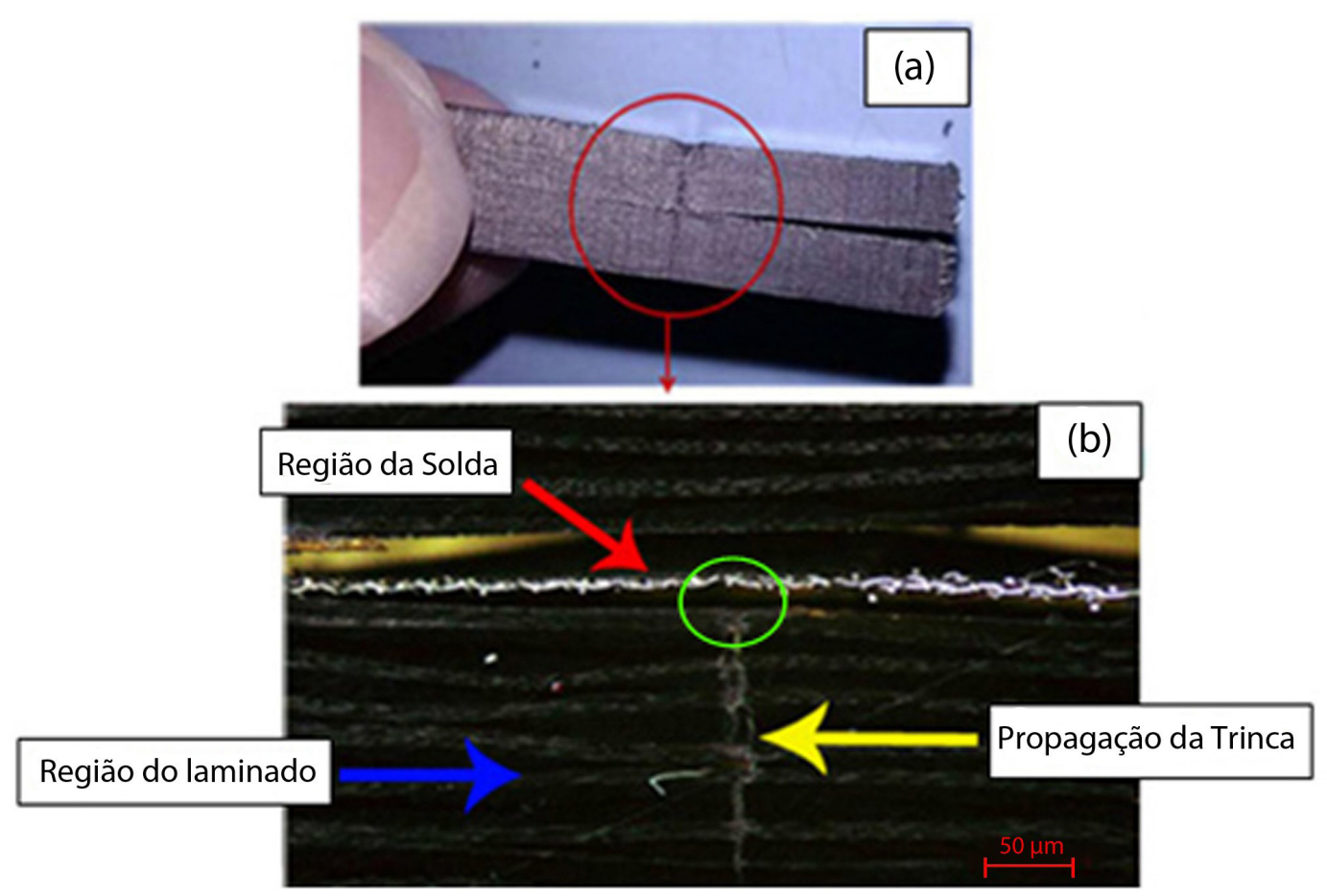

Figura 10. (a) Amostra de compósito PEI/fibra de carbono soldado após o ensaio de ILSS; (b) Micrografia apresentando o início da fratura na região fraturada pelo ensaio de ILSS do laminado PEI/fibra de carbono soldado.

sob o modo I e o modo II. Desta forma, fraturas interlaminares descrevem falhas orientadas entre as camadas, ocorrendo no plano do laminado, fraturando principalmente a matriz, com poucas ou nenhuma fratura de fibra. Fraturas translaminares são aquelas que ocorrem transversalmente ao plano do laminado, causando um significativo rompimento das fibras. Normalmente, encontram-se componentes que apresentam os três tipos de fratura simultaneamente $[26,27]$.

Para o ensaio losipescu, a análise do modo de falha interfacial possibilitou verificar a qualidade da adesão fibra/resina, que é uma condição essencial para explicar a resistência ao cisalhamento interlaminar neste método de ensaio. Esta tendência de aumento de resistência mecânica para as amostras soldadas foi observada nos resultados obtidos a partir dos ensaios de losipescu, uma vez que foi evidenciado que a soldagem alterou os valores da tensão de cisalhamento, ocorrendo um aumento de aproximadamente $20 \%$ na resistência ao cisalhamento do ensaio de losipescu. Este resultado corrobora com os encontrados a partir do ensaio de cisalhamento ILSS e pode ser explicado pela presença da malha metálica fornecer uma resistência adicional aos esforços cisalhantes.

Uma análise fractográfica envolvendo os laminados submetidos ao cisalhamento losipescu foi realizada neste trabalho por microscopia óptica. Desta forma, as micrografias ilustradas nas Figuras 11 e 12 evidenciam as imagens ampliadas dos corpos de prova após estes serem ensaiados na região do entalhe evidenciada na Figura 13.

Nas Figuras 11 e 12, pode ser observado que em ambos os casos ocorreram fraturas interlaminares e translaminares quando solicitado por cisalhamento losipescu, mostrando que para esta solicitação mecânica, a presença da malha metálica não interferiu, a princípio, consideravelmente na morfologia da fratura. Porém, realizando uma análise mais aprofundada pode ser observada, a partir da Figura 11 (laminado não soldado), uma fratura provavelmente evidenciada por um processo de microflambagem seguido de uma fratura translaminar mais intensa da que ocorre em materiais soldados.

\subsection{Tenacidade à fratura interlaminar $\boldsymbol{G}_{\| l c}$}

A resistência de materiais compósitos à delaminação pode ser bem caracterizada pela resistência à fratura interlaminar (cisalhamento no plano), medido como a energia dissipada por unidade de área de crescimento da trinca [28]. Um dos parâmetros mais importantes na aplicação da mecânica da fratura em estruturas de compósitos 
Avaliação da Resistência Interlaminar do Compósito PEl/Fibras de Carbono Soldado pelo Método de Resistência Elétrica

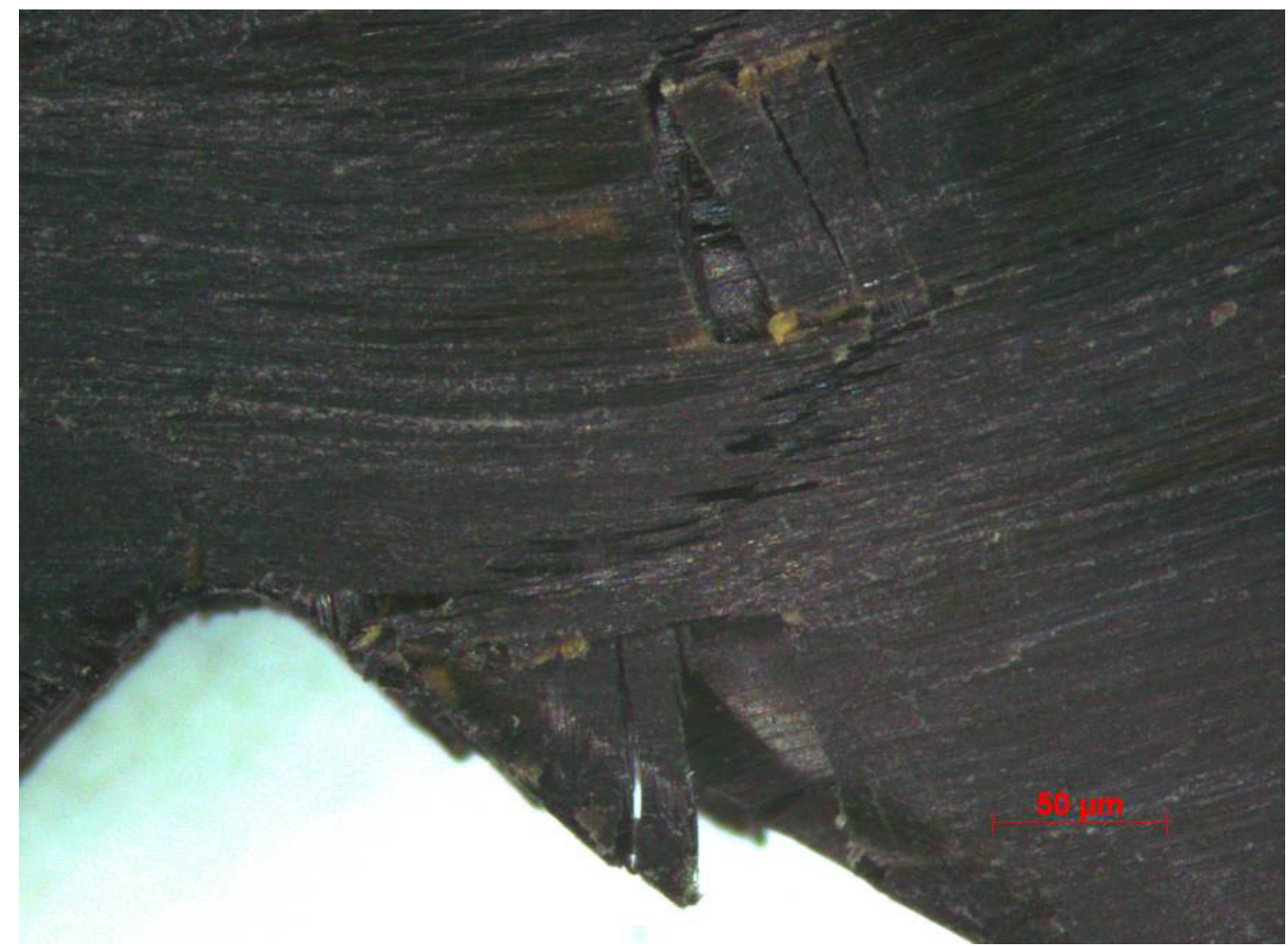

Figura 11. Imagem por microscopia óptica do laminado não soldado após o ensaio de losipescu, com ampliação de $8 X$.

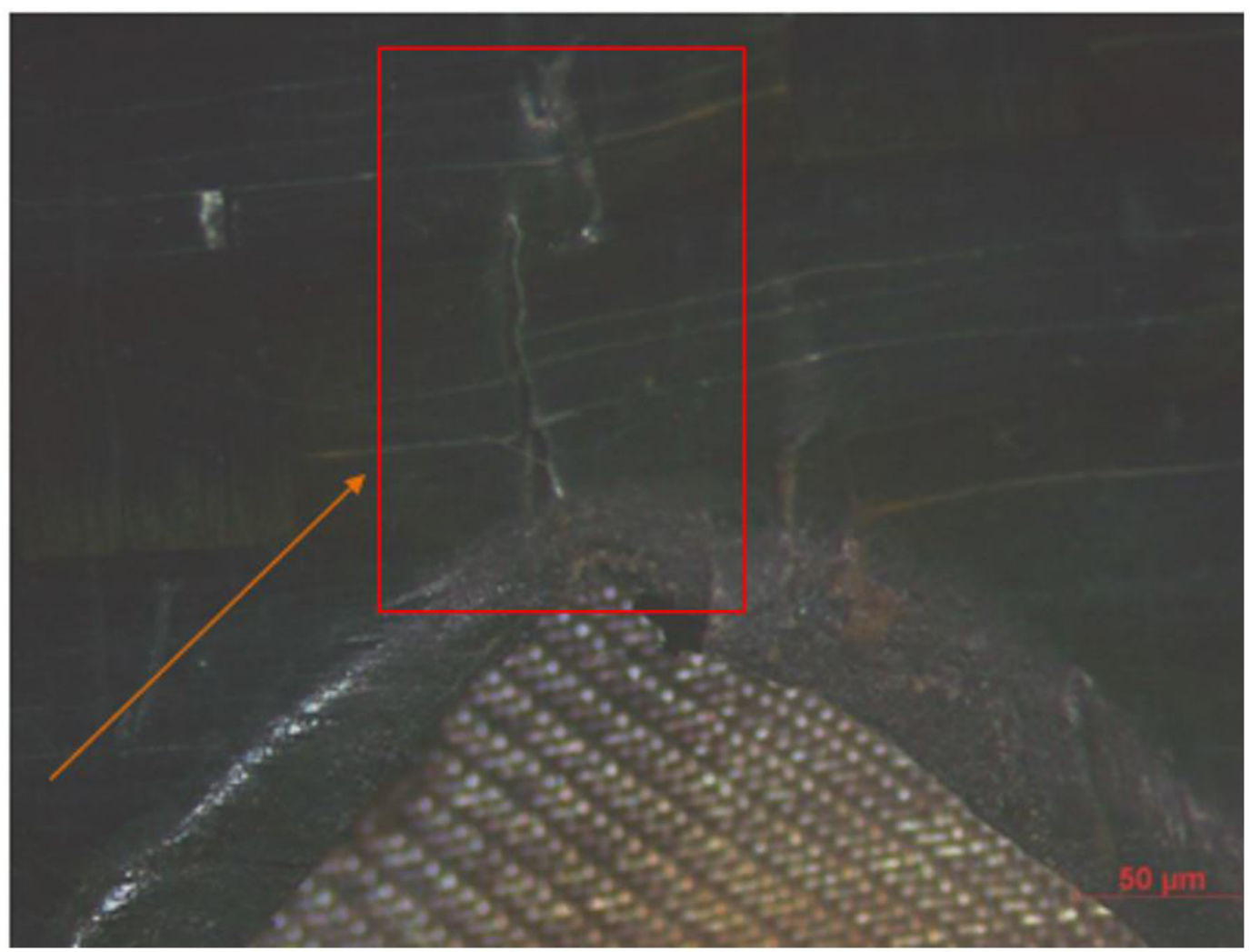

Figura 12. Imagem por microscopia óptica do laminado soldado após o ensaio de losipescu, com ampliação de 8 X. 


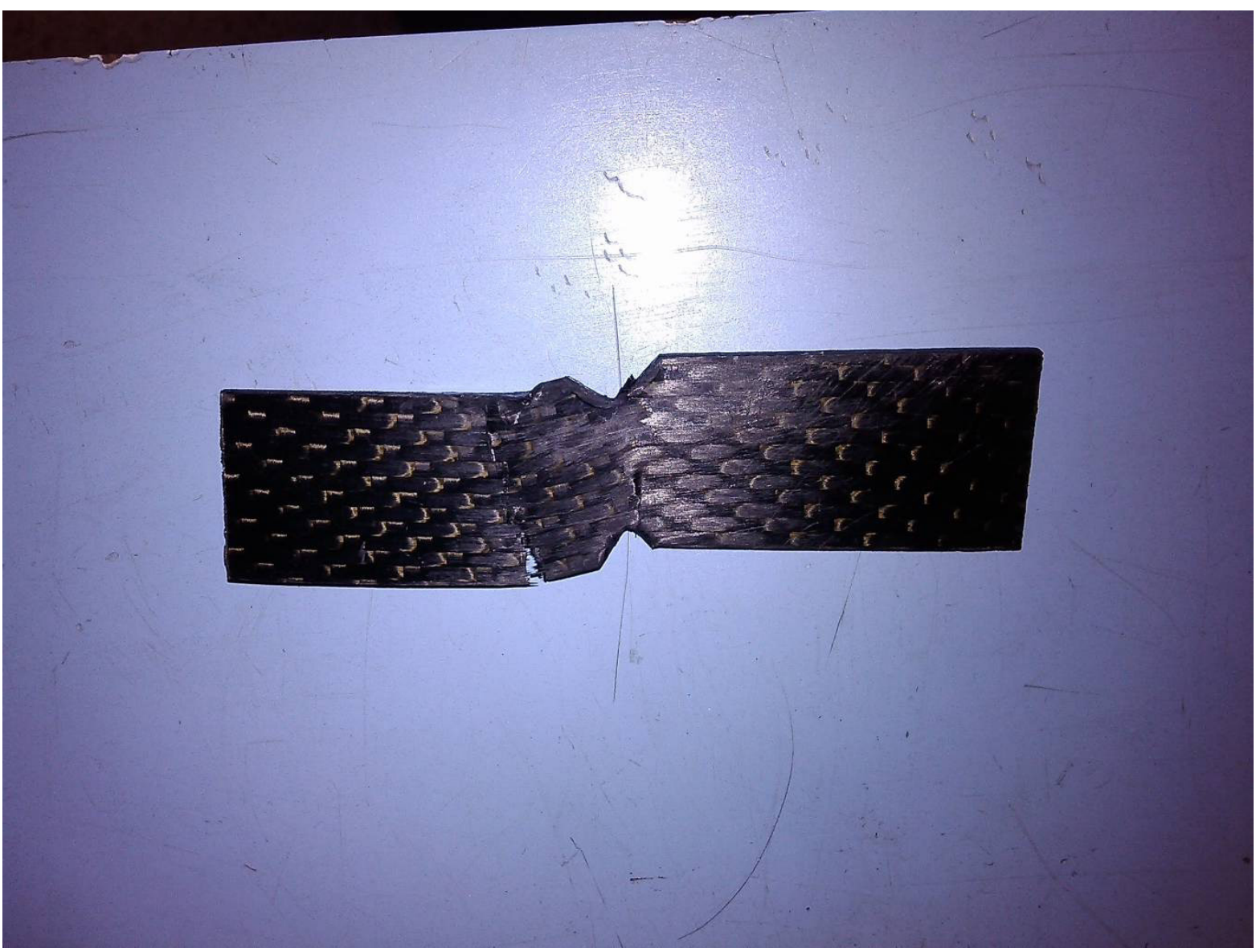

Figura 13. Amostra ensaiada do compósito PEl/fibra de carbono.

consiste na taxa de liberação de energia de deformação (G). Com a finalidade de determinar a taxa de liberação de energia de deformação crítica, experimentos de fratura devem ser realizados [29,30].

O modo II de delaminação não vem sendo muito estudado para compósitos soldados, o que pode ser explicado por algumas dificuldades inerentes aos ensaios experimentais necessários para este propósito, entretanto, o teste ENF (End-Notched Flexure) é o mais utilizado para a determinação desse modo de fratura [30,31]. Além disso, em muitas situações reais, as delaminações propagam-se predominantemente em modo II, como é o caso de placas de compósitos sob impacto a baixas velocidades [28,32]. Na Tabela 3 são apresentados os valores obtidos do ensaio de ENF em laminados PEI/Carbono soldados, apresentando os valores da força necessária para iniciar a propagação da trinca e, consequentemente, a obtenção do valor na energia crítica necessária para propagar a trinca no modo de falha II, $G_{\| l c}$. Adicionalmente, está apresentado o valor médio de $G_{\| l c}$ e o desvio padrão.

Tabela 3. Resultados obtidos com o ensaio de ENF para o laminado PEI/fibra de carbono soldado.

\begin{tabular}{cc}
\hline PEI/Carbono Soldado & Tenacidade a Fratura Interlaminar $\mathbf{G}_{\| \mathbf{c}}\left(\mathbf{J} / \mathbf{m}^{2}\right)$ \\
1 & 1171 \\
2 & 2089 \\
3 & 1628 \\
4 & 1610 \\
5 & 1986 \\
Média & 1687 \\
Desvio Padrão & 333 \\
\hline
\end{tabular}


Avaliação da Resistência Interlaminar do Compósito PEl/Fibras de Carbono Soldado pelo Método de Resistência Elétrica

O valor médio encontrado no presente trabalho para a tenacidade à fratura no modo Il é coerente com os valores desta propriedade reportados na literatura (entre 1159 a $1862 \mathrm{~J} / \mathrm{m}^{2}$ ) [33]. A Figura 14 apresenta duas curvas de Força X Deslocamento de laminados soldados obtida pelo ensaio ENF. Observa-se na Figura 14a, b que apesar das amostras terem sido soldadas com os mesmos parâmetros, a carga máxima obtida pela curva (a) é maior se comparada ao obtida pela curva (b) (2000 N a $1600 \mathrm{~N}$, respectivamente). Entretanto, a curva (b) obteve-se um deslocamento maior do que na curva (a) (10 mm e $6,8 \mathrm{~mm}$, respectivamente). Isto se deve ao fato da existência dos vários problemas inerentes aos testes habituais utilizados para a caracterização do modo Il da fratura interlaminar como, por exemplo, a propagação de fissuras instáveis [14].

Como descrito na literatura [14,23,24], problemas relacionados com o crescimento instável de trinca e o seu monitoramento durante a propagação podem dificultar uma medição rigorosa dos valores de $G_{\| c}$. Estas dificuldades
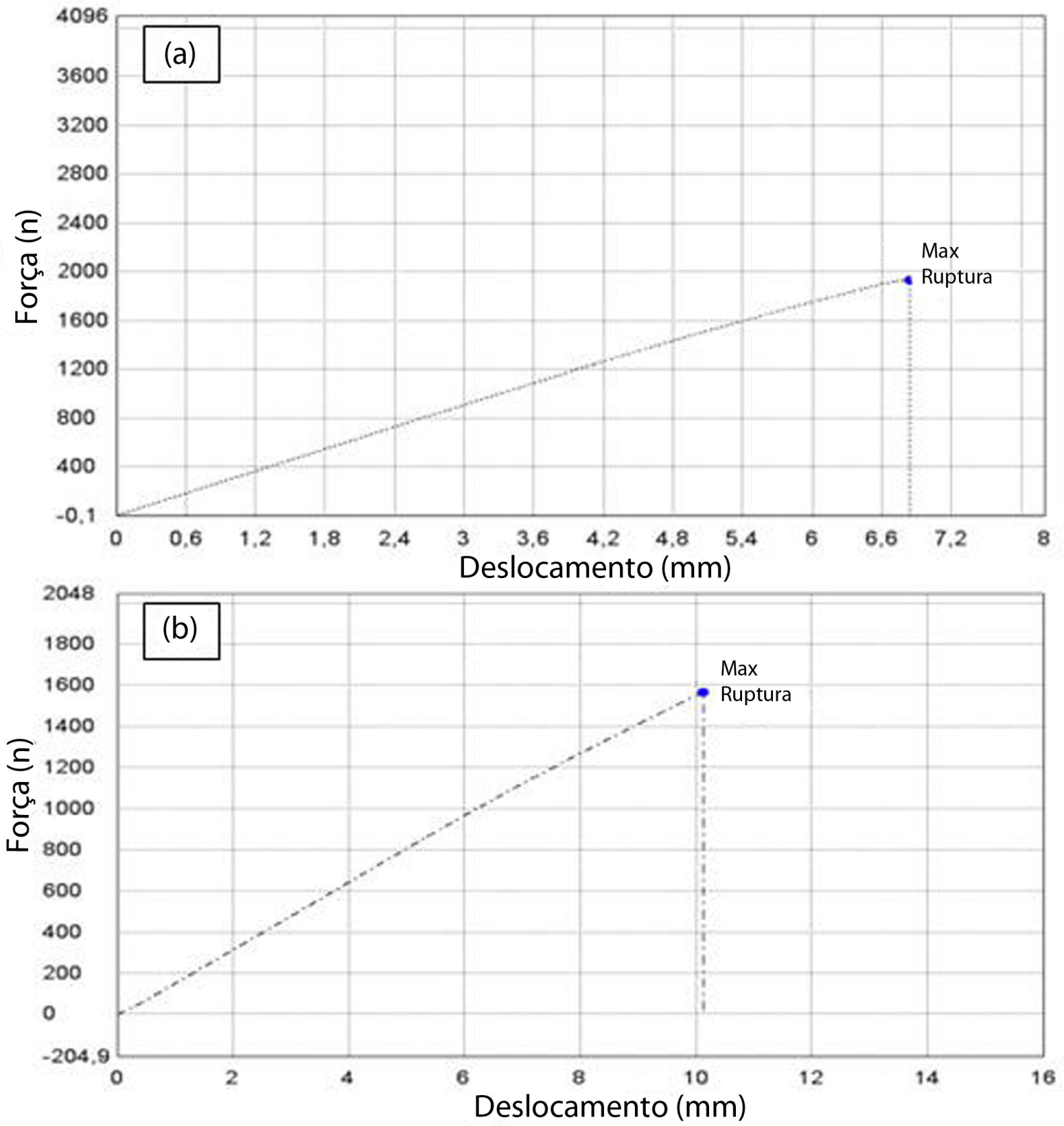

Figura 14. Curva Carga $x$ Deslocamento de laminados soldados: (a) Carga máxima: $2062 \mathrm{~N}$, Deslocamento: 6,8 mm; (b) Carga máxima: $1567 \mathrm{~N}$, Deslocamento: 10,1 mm. 
do ensaio inerentes ao crescimento instável da trinca poderiam explicar a diferença do valor de tenacidade a fratura interlaminar (Tabela 3) entre a amostra 1 do PEI/carbono $\left(1171,4 \mathrm{~J} / \mathrm{mm}^{2}\right)$ e a amostra $2\left(2089,8 \mathrm{~J} / \mathrm{mm}^{2}\right)$.

As Figuras 15a, b apresentam o momento em que a fratura acontece e como ocorre a propagação da trinca. A Figura 15a exibe, evidenciado por setas, o percurso da trinca que ocorre no sentido da maior força de tensão em que o material está sendo submetido. A Figura $15 \mathrm{~b}$ apresenta delaminação das camadas (falha interlaminar) dos laminados soldados em resposta a essa propagação da trinca, numa ampliação maior e mais detalhada.

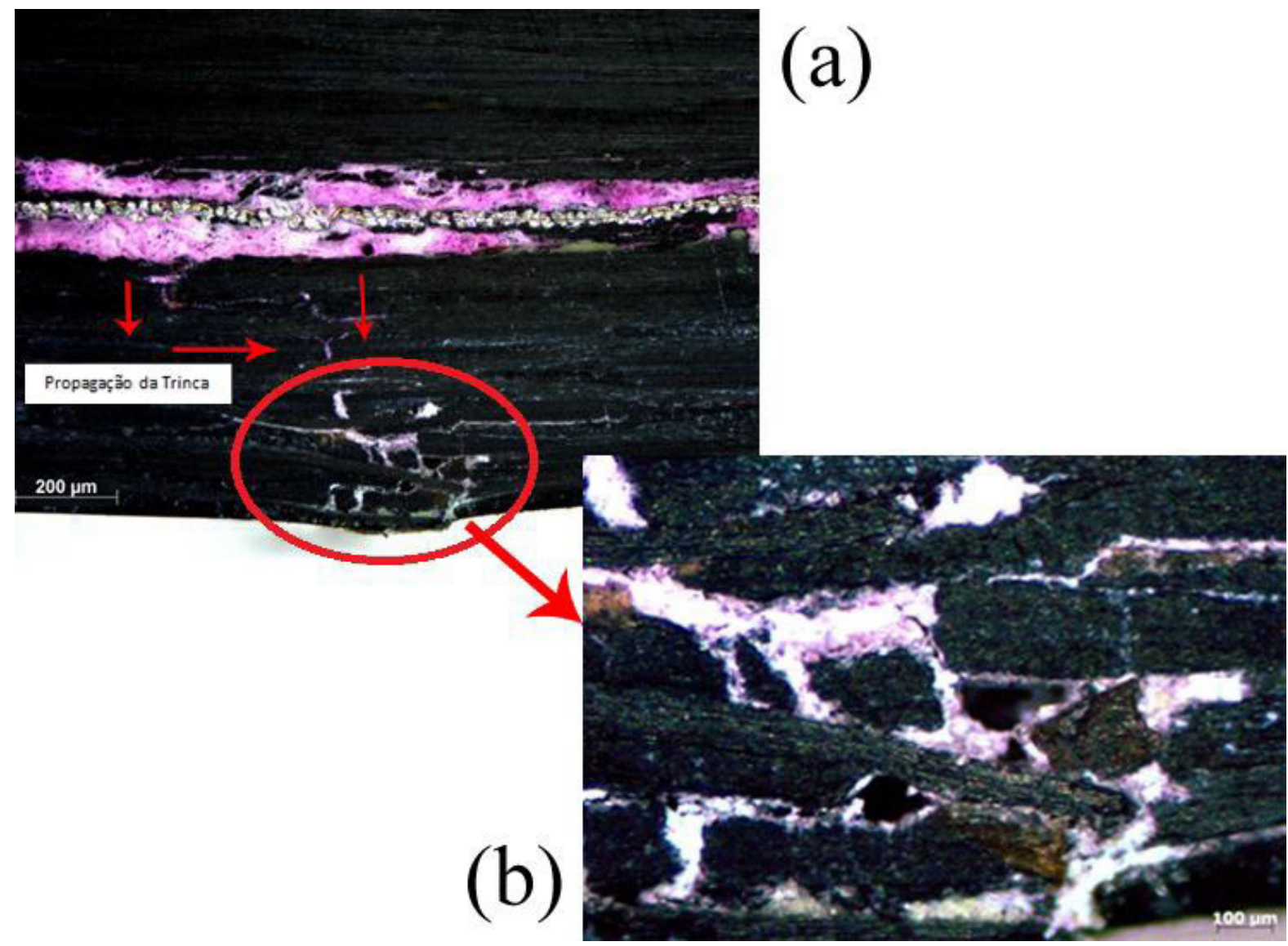

Figura 15. Propagação da trinca no laminado soldado no momento da fratura: (a) ampliação de 10x; (b) ampliação de $20 x$.

\section{Conclusões}

A partir dos resultados obtidos pelas técnicas de análise térmica empregadas neste trabalho, foi estabelecida a janela de temperatura que pode ser utilizada neste processo de soldagem. Adicionalmente, foi observado que para os laminados soldados, ocorreu um aumento de aproximadamente $15 \%$ na temperatura de transição vítrea, resultando em temperaturas mais elevadas de processamento.

A análise da tensão de cisalhamento interfacial obtida a partir dos ensaios de losipescu e ILSS sugeriu que o processo de soldagem por resistência foi realizado com sucesso, uma vez que foram observados ganhos significativos nesta propriedade quando amostras soldadas são comparadas com não soldadas.

Não há na literatura muitos resultados obtidos da tenacidade à fratura interlaminar do modo Il de laminados soldados, seja pelo processo de resistência elétrica ou por outro método de soldagem. A partir dos resultados provenientes do ensaio ENF, a média dos valores da tenacidade à fratura interlaminar do modo II (cisalhamento no plano) encontrados no estudo $\left(1619,4 \mathrm{~J} / \mathrm{m}^{2}\right)$ também foi similar a valores que há disponíveis na literatura $\left(670-1862 \mathrm{~J} / \mathrm{m}^{2}\right)$. A importância desse resultado para o processo de soldagem é em relação à verificação de 
Avaliação da Resistência Interlaminar do Compósito PEl/Fibras de Carbono Soldado pelo Método de Resistência Elétrica

qualidade da junta soldada, para assegurar a vida útil em serviço desse material soldado em estruturas aeronáuticas. A determinação da energia não evita, por si só, a falha da junta. A manutenção desta energia acima de valores mínimos, possivelmente, pode-se evitar as falhas comumente encontradas pra esse tipo de solicitações do material em serviço. Adicionalmente, com a análise morfológica de laminados fraturados pelo ensaio ENF foi verificado que a trinca se propaga em direção do plano dos laminados unidos adjacentes ao elemento resistivo, que tende a desviar-se do plano em favor das principais tensões máximas de cisalhamento a qual o material foi submetido.

\section{Agradecimentos}

Os autores gostariam de agradecer à FAPESP e ao CNPq, pelo auxílio financeiro disponibilizado para a realização deste trabalho.

\section{Referências}

[1] Ageorges YE, Ye L, Hou M. Experimental investigation of the resistance welding for thermoplastic-matrix composites. Part I: heating element and heat transfer. Composites Science and Technology. 2000;60(7):1027-1039. http://dx.doi.org/10.1016/ S0266-3538(00)00005-1.

[2] Stavrov D, Bersee HEN. Resistance Welding of Thermoplastic Composites-an Overview. Composites. Part A, Applied Science and Manufacturing. 2005;36(1):39-54. http://dx.doi.org/10.1016/ S1359-835X(04)00182-4.

[3] Nino GF, Ahmed TJ, Bersee HEN, Beukers A. Thermal NDI of resistance welded composite structures. Composites. Part B, Engineering. 2009;40(3):237-248. http://dx.doi.org/10.1016/j. compositesb.2008.10.003.

[4] Stavrov D, Bersee HEN. Thermal aspects in resistance welding of thermoplastic composites. In: ASME 2003 Heat Transfer Summer Conference; 2003; Las Vegas, Nevada, USA. New York: ASME; 2003. (vol. 3).

[5] Oliveira GH, Guimarães VA, Botelho EC. Influência da temperatura no desempenho mecânico de compósitos PEl/fibras de vidro. Polímeros. 2009;19(4):305-312. http://dx.doi.org/10.1590/ S0104-14282009000400010.

[6] Yuan Q, Hou M, Mai Y-W, Ye L. Resistance welding of carbon fiber reinforced polyetherimide composit. Journal of Thermoplastic Composite Materials. 2001;14(1):2-19. http://dx.doi.org/10.1106/ XF4F-6NEH-9KGN-1Y4R.

[7] Salleh WNW, Ismail AF, Matsuura T, Abdullah MS. Precursor selection and process conditions in the preparation of carbon membrane for gas separation: a review. Separation \& Purification Reviews. 2011;40(4):261-311. http://dx.doi.org/10.1080/1542 2119.2011.555648

[8] Costa AP, Botelho EC, Costa ML, Narita NE, Tarpani JR. A review of welding technologies for thermoplastic composites in aerospace applications. Journal of Aerospace Technology and Management. 2009;4(3):255-262. http://dx.doi.org/10.5028/ jatm.2012.040303912

[9] Amancio-Filho ST. Rebitagem por fricção ("FricRiveting"): desenvolvimento de uma nova técnica de união para juntas híbridas do tipo polímero-metal. Parte I: processo e microestrutura. Soldagem e Inspeção. 2011;55(4):387-395. http://dx.doi.org/10.1590/S0104-92242011000400010.

[10] Yousefpour A, Hojjati M, Immarigeon J-P. Fusion bonding/ welding of thermoplastic composites. Journal of Thermoplastic Composite Materials. 2004;17(4):303-341. http://dx.doi. org/10.1177/0892705704045187.

[11] De Baere I, Jacques S, Van Paepegem W, Degrieck J. Study of the mode i and mode II interlaminar behaviour of a carbon fabric

reinforced thermoplastic. Polymer Testing. 2012;31(2):322-332. http://dx.doi.org/10.1016/j.polymertesting.2011.12.009.

[12] Mathews MJ, Swanson SR. Characterization of the interlaminar fracture toughness of a laminated carbon/epoxy composite. Composites Science and Technology. 2007;67(7-8):1489-1498. http://dx.doi.org/10.1016/j.compscitech.2006.07.035.

[13] De Morais AB, et al. Mode-I interlaminar fracture of carbonepoxy cross-ply composites. Composites Science and Technology. 2002;62(5):679-686. http://dx.doi.org/10.1016/ S0266-3538(01)00223-8.

[14] Wang WX, Nakata M, Takao Y, Matsubara T. Experimental investigation on test methods for mode II interlaminar fracture testing of carbon fiber reinforced composites. Composites. Part A, Applied Science and Manufacturing. 2009;40(9):14471455. http://dx.doi.org/10.1016/j.compositesa.2009.04.029.

[15] Nogueira CL. Obtenção e caracterização de compósitos termoplásticos avançados à base de matrizes de polipropileno reforçados com fibra de carbono [tese de doutorado]. São José dos Campos: Instituto Tecnológico de Aeronáutica; 2004.

[16] Azevedo DAS. Sistema para determinação da temperatura de transição vítrea de adesivos [dissertação de mestrado]. Porto: Faculdade de Engenharia da Universidade de Porto, Universidade do Porto; 2014.

[17] Labrandero, S.D. Characterization of metallic meshes used for resistance welding of thermoplastic composites [monografia]. Madrid: Faculty of Aerospace Engineering Design and Production of Composite Structures, Universidad Carlos III de Madrid; 2009.

[18] Abrahão ABRM. Otimização do processo de soldagem por resistência elétrica em compósitos $\mathrm{PEI} / \mathrm{fibras}$ contínuas para aplicações aeronáuticas [tese de doutorado]. Guaratinguetá: Faculdade de Engenharia de Guaratinguetá, Universidade Estadual Paulista; 2015

[19] Abrahão ABMR, Reis JF, Brejao SD, Ribeiro VG, Costa ML, Botelho EC. Avaliação dos parâmetros tempo, corrente e pressão na soldagem por resistência elétrica de compósitos $\mathrm{PE}$ / fibras cont nuas: influência na resistência mecânica. Revista Matéria. 2015;20(2):530-543. http://dx.doi.org/10.1590/ S1517-707620150002.0053

[20] Wise RJ. Thermal welding of polymers. Cambridge: Woodhead Publishing; 1999.

[21] Neto LF, Pardini LC. Compósitos estruturais. São Paulo: Edgard Blücher; 2006. $313 \mathrm{p}$.

[22] Conejo LDS. Obtenção e caracterização térmica de compósitos nanoestruturados de resina fenol-furfurílica/cnt [dissertação 
de mestrado]. Guaratinguetá: Faculdade de Engenharia do Campus de Guaratinguetá, Universidade Estadual Paulista; 2015.

[23] Harper CA. Handbook of plastics, elastomers and composites. 3. ed. New York: McGraw-Hill; 1996. 757 p.

[24] Marques LS, Narita NE, Costa GG, Rezende MC. Avaliação dos comportamentos mecânico e térmico de laminados de PPS/ fibra de carbono processados em autoclave sob diferentes ciclos de consolidação. Polímeros. 2010;20(4):309-314. http://dx.doi.org/10.1590/S0104-14282010005000049.

[25] Arrese A, Carbajal N, Vargas G, Mujika F. A new method for determining mode II R-curve by the End-Notched Flexure test. Engineering Fracture Mechanics. 2010;77(1):51-70. http://dx.doi.org/10.1016/j.engfracmech.2009.09.008.

[26] Botelho EC, Rezende MC. Caracterização mecânica de compósitos de poliamida/fibra de carbono via ensaios de cisalhamento interlaminar e de mecânica da fratura. Polímeros. 2002;12(3):153-163. http://dx.doi.org/10.1590/ S0104-14282002000300007.

[27] Cândido GM, Rezende MC, Donadon MV, Almeida SFM. Fractografia de compósito estrutural aeronáutico submetido à caracterização de tenacidade à fratura interlaminar em modo I. Polímeros. 2012;22(1):41-53. http://dx.doi.org/10.1590/ S0104-14282012005000019.
[28] Arrese A, Mujika F. Influence of bending rotations on three and four-point bend end notched flexure tests. Engineering Fracture Mechanics. 2008;75(14):4234-4246. http://dx.doi. org/10.1016/j.engfracmech.2008.03.012.

[29] Baley C, Davies P, Grohens Y, Dolto G. Application of Interlaminar tests to marine composites: a literature review. Applied Composite Materials. 2004;11(2):99-126. http://dx.doi. org/10.1023/B:ACMA.0000012902.93986.bf.

[30] Sun CT, Zheng S. Delamination characteristics of doublecantilever beam and end-notched flexure composite specimens. Composites Science and Technology. 1996;56(4):451-459. http:// dx.doi.org/10.1016/0266-3538(96)00001-2.

[31] De Morais AB. Novel cohesive beam model for the End-Notched Flexure (ENF) specimen. Engineering Fracture Mechanics. 2011;78(17):3017-3029. http://dx.doi.org/10.1016/j. engfracmech.2011.08.019.

[32] Choi HY, Chang FK. A model for predicting damage in graphite/ epoxy laminated composites resulting from low-velocity point impact. Journal of Composite Materials. 1992;26(14):2134-2169. http://dx.doi.org/10.1177/002199839202601408.

[33] Yuan Q, Hou M, Mai Y-W, Ye L. resistance welding of carbon fiber reinforced polyetherimide composit. Journal of Thermoplastic Composite Materials. 2001;14(1):2-19. http://dx.doi.org/10.1106/ XF4F-6NEH-9KGN-1Y4R. 